JIOM Nepal. Volume 41 Number 3. December 2019, page 8-12.

\title{
Prevalence of Laryngopharyngeal Reflux in Patients with Gastroesophageal Reflux Disease Undergoing Upper Esophagogastroduodenoscopy
}

\author{
Sangita R Chalise', Subash Khadka', Rupesh Mukhia ${ }^{2}$, Abishek Thapa², Santosh Gautam³ ${ }^{3}$ Mukesh \\ Sah $^{3}$, Rashmi Ranjan ${ }^{1}$ \\ ${ }^{1}$ Department of ENT \& HNS, ${ }^{2}$ Department of Surgery, ${ }^{3}$ Department of Internal Medicine, KIST Medical College \\ Teaching Hospital, Lalitpur, Nepal
}

Corresponding author:

Sangita Regmi Chalise, MBBS, MS

Department of ENT \& HNS, KIST Medical College Teaching Hospital, Lalitpur, Nepal

Email:sangitaregmi@gmail.com

Submitted : November 2, 2019

Accepted : December 8, 2019

\begin{abstract}
Introduction

Gastroesophageal reflux disease (GERD) has been defined as the retrograde flow of gastric contents into the esophagus. Laryngopharyngeal reflux (LPR) is one of the manifestations of GERD which can be diagnosed clinically by Reflux Symptom Index (RSI) and Reflux Finding Score (RFS). The aim of this study was to find the prevalence of laryngopharyngeal reflux in patients with GERD undergoing upper esophagogastroduodenoscopy.
\end{abstract}

\section{Methods}

This was a prospective cross sectional study and all the patients visiting author's institute with GERD undergoing upper esophagogastroduodenoscopy were included. All the relevant data on history, examination, RSI scores, RFS scores and upper esophagogastroduodenoscopy findings were recorded in the standard proforma and data were analysed.

\section{Results}

A total of 205 patients with GERD and undergoing upper esophagogastroduodenoscopy were included whose mean age was 46.1 years. The female to male ratio was $1.3: 1$. The most common presenting symptoms in our study was hoarseness (97\%) followed by coughing (90.7\%). The mean RSI score was 11.6 . The symptom prevalence of LPR was $23.4 \%$. The prevalence in between age groups and gender was not significantly different. The mean RFS score was 9.5. The prevalence of LPR by RFS assessment was $64.4 \%$, which is significantly more than the prevalence assessed by RSI (23.4\%).

\section{Conclusion}

The prevalence of LPR in patients with GERD by RSI was less than the prevalence by RFS. So both the tools need to be used simultaneously to make the diagnosis and not recommendable to use independently.

Keywords: Gastroesophageal reflux disease, laryngopharyngeal reflux, reflux finding score, reflux symptom index

\section{INTRODUCTION}

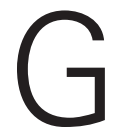
astroesophageal reflux (GERD) has been defined as the retrograde flow of gastric contents into the esophagus. Many patients have the classic symptoms of heartburn and regurgitation. A smaller group of patients present with primarily otolaryngologic manifestations of
GERD, which has been termed laryngopharyngeal reflux (LPR). The condition was first described by Koufman in 1991. ${ }^{1}$ LPR is a syndrome associated with a constellation of symptoms including hoarse voice, chronic cough, and other complaints that are usually treated by ENT surgeons. It is believed to be caused by the retrograde flow of stomach 
contents into the laryngopharynx, which is an extra-esophageal manifestation of GERD. ${ }^{2}$ Many patients can have the laryngeal findings but does not have clinical symptoms and may land up with irreversible and severe complications. It is prudent to diagnose the LPR and advice appropriate treatment even for asymptomatic patients. LPR is increasingly cited as cause of laryngeal signs and symptoms such as globus sensation, hoarseness, chronic cough, chronic throat clearing, and throat pain. The diagnosis of LPR is usually made on the basis of presenting symptoms and associated laryngeal signs including laryngeal edema and erythema. ${ }^{3}$ However main diagnostic approach to LPR, by most of ENT\&HN surgeons, depend on clinical history and laryngeal examination. ${ }^{2}$ For the proper diagnosis, LPR is defined by Reflux Symptom Index (RSI) and Reflux Finding Score (RFS) ${ }^{4,5} \mathrm{RSI}$ is a validated self-administered questionnaires used to access the clinical severity of symptoms at diagnosis and treatment. The maximum score for $\mathrm{RSI}$ is forty-five. It is considered significant when the RSI is more than 13 scores. ${ }^{4}$ RFS is an eight items clinical severity scale, introduced by Belafsky et al, which is widely used in the diagnosis of LPR. The worst score on RFS is twenty-six and score above seven is considered abnormal. ${ }^{5}$ Thus, the objective of the study was to know the prevalence of LPR in symptomatic GERD patients undergoing upper esophagogastroduodenoscopy using RSI and RFS tools.

\section{METHODS}

This prospective cross-sectional hospital based study was conducted at author's institute during a period of one year from June 2018 to May 2019. All the patients who were clinically diagnosed with GERD and undergoing upper esophagogastroduodenoscopy were enrolled in the study. Patients who had previous upper esophagogastroduodenoscopic

examinations were excluded from the study. Ethical approval was obtained from the institutional review committee and informed consent was taken from participants prior to the study.

All patients were assessed prior to upper esophagogastroduodenoscopy with clinical history, ear nose throat and head and neck (ENT \& HN) examinations. Patients were asked to fill the RSI proforma at outpatient department. The proforma consists of nine symptoms related to LPR viz hoarseness, throat clearing, postnasal drip, difficulty in swallowing etc, and rated them into scale 0 to 5 according to severity. ${ }^{4}$ Upper esophagogastroduodenoscopy was performed with flexible esophagogatroduodenoscope (Pentax, Model EPK-i5000) under local anaesthesia by gastro surgeons and gastroenterologists. Laryngeal findings were evaluated and noted by the otolaryngologist during the procedure. RFS proforma, which consists of eight different laryngeal findings, was filled and entered into the data sheet. ${ }^{5}$ The scale ranges from 0 (no abnormal findings) to a maximum of 26 (worst possible score). LPR was diagnosed when RSI and RFS scores were more than 13 and seven respectively. ${ }^{6-8}$

Data from filled proforma was entered and analysed using the SPSS Statistics for Windows v25. Chi-square test was used to compare means and Pearson's correlation coefficient was used to assess the association between various parameters. The level of significance for all tests was set at $p<0.05$.

\section{RESULTS}

A total of 205 patients who were clinically diagnosed with GERD and undergoing upper esophagogastroduodenoscopy were included in

Table 1. Severity of symptoms in Reflux Symptom Index (RSI)

\begin{tabular}{|c|c|c|c|c|c|c|}
\hline \multirow{2}{*}{$\begin{array}{l}\text { Within the past month, how did the following } \\
\text { problems affect you? }\end{array}$} & \multicolumn{6}{|c|}{$0=$ No problem, $5=$ Severe problem } \\
\hline & 0 & 1 & 2 & 3 & 4 & 5 \\
\hline - Hoarseness or a problem with your voice? & $1 \%$ & $97 \%$ & $2 \%$ & $0 \%$ & $0 \%$ & $0 \%$ \\
\hline - Clearing your throat? & $1 \%$ & $78 \%$ & $19 \%$ & $1.5 \%$ & $0.5 \%$ & $0 \%$ \\
\hline - Excess throat mucus or postnasal drip? & $0.5 \%$ & $86.3 \%$ & $12.2 \%$ & $1 \%$ & $0 \%$ & $0 \%$ \\
\hline - Difficulty swallowing food, liquids or pills? & $1 \%$ & $86.8 \%$ & $11.2 \%$ & $1 \%$ & $0 \%$ & $0 \%$ \\
\hline - Coughing after you ate or lie down? & $1 \%$ & $90.7 \%$ & $7.8 \%$ & $0.5 \%$ & $0 \%$ & $0 \%$ \\
\hline - Breathing difficulties or choking episodes? & $1 \%$ & $82.4 \%$ & $13.2 \%$ & $2.9 \%$ & $0.5 \%$ & $0 \%$ \\
\hline - Troublesome or annoying cough? & $1 \%$ & $83.9 \%$ & $13.7 \%$ & $1 \%$ & $0.5 \%$ & $0 \%$ \\
\hline \multirow{2}{*}{$\begin{array}{l}\text { - Sensations of something sticking in your } \\
\text { throator a lump in your throat? } \\
\text { - Heartburn, chest pain, indigestion, or stomach } \\
\text { acidcoming up? }\end{array}$} & $0.5 \%$ & $50.2 \%$ & $45.4 \%$ & $3.9 \%$ & $0 \%$ & $0 \%$ \\
\hline & $0 \%$ & $17.6 \%$ & $57.6 \%$ & $15.6 \%$ & $8.8 \%$ & $0.5 \%$ \\
\hline
\end{tabular}


Table 2. Severity of symptoms in Reflux Finding Score (RFS)

\begin{tabular}{lcc}
\hline \multicolumn{1}{c}{ Symptoms } & Scores & Frequency (\%) \\
\hline Subglottic edema & & \\
- Absent & 0 & $127(62)$ \\
- Present & 2 & $78(38)$ \\
Ventricular obliteration & & \\
- Absent & 0 & $14(6.8)$ \\
- Partial & 2 & $176(85.9)$ \\
- Complete & 4 & $15(7.3)$ \\
Erythema/hyperemia & & \\
- Absent & 0 & $16(7.9)$ \\
- Arytenoids only & 2 & $163(79.4)$ \\
- Diffuse & 4 & $26(12.7)$ \\
Vocal fold edema & & \\
- None & 0 & $4(2)$ \\
- Mild & 1 & $147(71.6)$ \\
- Moderate & 2 & $51(24.9)$ \\
- Severe & 3 & $3(1.5)$ \\
- Polypoid & 4 & $0(0)$ \\
Diffuse laryngeal edema & & \\
- None & & $5(2.4)$ \\
- Mild & 0 & $141(68.8)$ \\
- Moderate & 1 & $52(25.4)$ \\
- Severe & 2 & $0(3.4)$ \\
- Obstructing & 3 & $0(0)$ \\
Posterior commissure & 4 & \\
hypertrophy & & \\
- None & & \\
- Mild & & \\
- Moderate & & \\
- Severe & & \\
- Obstructing & & \\
Granuloma/granulation & & \\
- Absent & & \\
- Present & & \\
Thick endolaryngeal & & \\
mucus/other & & \\
- Absent & & \\
- Present & & \\
\hline
\end{tabular}

the study over a period of one year. The mean age of the patients was $46.1 \pm 16.1$ (range, 16-78) years. Maximum number of patients $(43,21 \%)$ were between 30-40 years.

One hundred and sixteen (56.6\%) were female and $89(43.4 \%)$ were male. The female to male ratio was $1.3: 1$. Twenty-eight patients $(13.7 \%)$ were smokers while 31 patients (15.1\%) were alcohol consumers.

The most common presenting symptoms in our study was hoarseness (97\%) followed by coughing $(90.7 \%$ ). The mean RSI score was 11.6 \pm 2.2 (range,
5-19). The distribution of severity of each symptom among the patients was summarised in Table 1. $R S I>13$ was considered as the clinical diagnosis of LPR, which was found in 48 patients (23.4\%). The prevalence of LPR in younger patients (less than 50 years) was $24.5 \%$ and older patients (more than 50 years) was $21.9 \%$, but the difference was not statistically significant ( $p$ value-0.66). Similarly, the prevalence among the male $(26.9 \%)$ and female (20.6\%) were also not statistically significant.

The mean scores of RFS was $9.5 \pm 3.2$ (range, 3-21). The distribution of severity of each laryngeal findings in the patients was summarised in Table 2. The prevalence of LPR by RFS assessment was $64.4 \%$, which is significantly more than the prevalence assessed by RSI (23.4\%). The prevalence of LPR assessed by RFS in between young and old patients and male and female were not statistically significant. (Table 3 )

The most common finding of upper esophagogastroduodenoscopy was antral gastritis $(42.4 \%)$ followed by peptic ulcer in $19 \%$ of cases. Normal findings were noted in $11.2 \%$ of patients who presented with clinical symptoms of GERD. (Table 4)

\section{DISCUSSION}

Laryngopharyngeal reflux is one of the extra digestive manifestation of gastroesophageal reflux disease. 9 Although GERD and LPR are considered to be a part of spectrum of same disease, they differ in their symptoms, clinical manifestations and responses to treatment. That is the reason behind to know the prevalence of LPR in the patients presented with GERD.

Most of our patients were in middle age and there was female preponderance. In the study done by Groome et al10, similar female preponderance has been reported (58.3\%).

In our study, $15.1 \%$ patients had history of alcohol intake and $13.7 \%$ were smoker. Those habits were strongly related to GERD and LPR. Vardar et al2 found more of smokers (52\%) than alcohol consumer $(6.5 \%)$ in their study.

The common presenting symptom in our study was hoarseness and similar symptom has been reported by Giacchi et al. ${ }^{11}$ In contrary, Tauber el al12 found dysphagia as the most common symptom (67\%) followed by hoarseness (53\%).

The mean RSI score in our study was 11.6. Lowden et al13 observed mean RSI score of $7 .^{3}$ in their study, which is much lower than our mean RSI score. The study group was general asymptomatic population whereas our study group was symptomatic GERD patients. The diagnosis of LPR was considered 
Table 3. Prevalence of laryngopharyngeal reflux (LPR) in patients with GERD undergoing upper esophagogastroduodenoscopy

\begin{tabular}{|c|c|c|c|c|c|c|c|}
\hline \multirow[t]{2}{*}{ Group } & \multirow[t]{2}{*}{ Number } & \multicolumn{2}{|c|}{$\begin{array}{l}\text { Reflux Symptom Index } \\
\text { (RSI) }\end{array}$} & \multirow[t]{2}{*}{$\mathrm{p}$-value } & \multicolumn{2}{|c|}{$\begin{array}{l}\text { Reflux Finding Score } \\
\text { (RFS) }\end{array}$} & \multirow[t]{2}{*}{$\mathrm{p}$-value } \\
\hline & & score $<13$ & score $>=13$ & & score $<=7$ & score $>7$ & \\
\hline Total patients & 205 & $157(76.6 \%)$ & $48(23.4 \%)$ & & $73(35.6 \%)$ & $132(64.4 \%)$ & \\
\hline $\begin{array}{l}\text { Age group } \\
\bullet<50 \text { years } \\
->50 \text { years }\end{array}$ & $\begin{array}{l}114 \\
91\end{array}$ & $\begin{array}{l}86(75.5 \%) \\
71(78.1 \%)\end{array}$ & $\begin{array}{l}28(24.5 \%) \\
20(21.9 \%)\end{array}$ & 0.66 & $\begin{array}{l}40(35.1 \%) \\
33(36.3 \%)\end{array}$ & $\begin{array}{l}74(64.9 \%) \\
58(63.7 \%)\end{array}$ & 0.48 \\
\hline $\begin{array}{l}\text { Sex } \\
\text { - Female } \\
\text { - Male }\end{array}$ & $\begin{array}{l}116 \\
89\end{array}$ & $\begin{array}{l}92(79.4 \%) \\
65(73.1 \%)\end{array}$ & $\begin{array}{l}24(20.6 \%) \\
24(26.9 \%)\end{array}$ & 0.29 & $\begin{array}{l}40(34.5 \%) \\
33(37.1 \%)\end{array}$ & $\begin{array}{l}76(65.5 \%) \\
56(62.9 \%)\end{array}$ & 0.4 \\
\hline
\end{tabular}

when RSI was more than 13 score. The prevalence of LPR by symptom assessment (RSI score) was $23.4 \%$ in our study group. In a study done at Turkey ${ }^{14}$, the prevalence of LPR was much higher $(69.8 \%)$ than ours. The reason could be that the study population were previously untreated patients who had presented with laryngeal lesions. In the study done by Kamani et al15, the mean RSI score was 8.3 giving an LPR symptom prevalence of $34.4 \%$ in English population. The comparison of LPR symptom prevalence between the young and elderly patients and between male and female were not statistically significant in our study. Vardar et $\mathrm{al}^{2}$ also didn't find any difference in prevalence between age $<50$ and age $>50$ years in their study.

The mean RFS score was 9.5 in our study and more than 7 score was considered abnormal. In a study done by Tezer et $\mathrm{al}^{16}$, the mean RFS score was 11.5. Similarly mean score was recorded to be 10 in a study by Vardar et al ${ }^{2}$. The finding prevalence of LPR by RFS score was higher than that assessed by RSI (64.4\% Vs $23.4 \%)$.

From the above findings, we can conclude that both the tools need to be used simultaneously to make the diagnosis and cannot be used independently. Hoon et $\mathrm{al}^{17}$, in their study, also reported the similar conclusion. A patient with GERD without laryngeal symptoms could have laryngeal findings as confirmed by our study. So

Table 4. Findings of upper esophagogastroduodenoscopy

\begin{tabular}{lc}
\hline \multicolumn{1}{c}{ Findings } & Frequency (\%) \\
\hline Antral gastritis & $87(42.4)$ \\
Peptic ulcer & $39(19)$ \\
Normal & $23(11.2)$ \\
Hiatus hernia & $18(8.8)$ \\
Oesophageal varices & $12(5.9)$ \\
Portal hypertensive gastropathy & $8(3.9)$ \\
\hline
\end{tabular}

the treating clinicians should be aware about this fact and need to send the patients for laryngeal evaluation to otolaryngologist.

Upper esophagogastroduodenoscopy was normal in $11.2 \%$ of clinically diagnosed GERD. In a study done at Korea by Park et al18 higher (41.9\%) incidence of normal endoscopic findings was reported. Their study population were patients who had laryngeal symptoms, and higher incidence was expected in those subset of patients.

Antral gastritis was most common findings followed by peptic ulcer in our study. Whereas in a study done by Somefun et al, ${ }^{19}$ duodenal ulcer was the most common finding (56.4\%).

\section{CONCLUSION}

The prevalence of LPR in patients with GERD by RSI was less than the prevalence by RFS. So both tools need to be used simultaneously to make the diagnosis and not recommendable to use independently.

\section{CONFLICT OF INTEREST}

None declared.

\section{REFERENCES}

1. Watkinson JC, Clarke RW. Scott-Brown's Otorhinolaryngology Head \& neck Surgery 8th ed. Florida: CRC Press; 2018. Chapter 77, Reflux Disease; p. 1093-98.

2. Vardar R, Varis A, Bayrakci B, Akyildiz S, Kirazli T, Bor S. Relationship between history, laryngoscopy and esophagogastroduodenoscopy for diagnosis of laryngopharyngeal reflux in patients with typical GERD. Eur Arch Otorhinolaryngol 2012;269:18791.

3. Farrokhi F, Vaezi MF. Laryngeal disorders in patients with gastroesophageal reflux disease. Minerva Gastroenterol Dietol 2007;53:181-7. 
4. Belafsky PC, Postma GN, Koufman JA. Validity and reliability of the reflux symptom index (RSI). Journal of voice 2002;16:274-7.

5. Belafsky PC, Postma GN, Koufman JA. The validity and reliability of the reflux finding score (RFS). The laryngoscope 2001;111:1313-7.

6. da Silva CE, Niedermeier BT, Portinho F. Reflux laryngitis: correlation between the symptoms findings and indirect laryngoscopy. Int'l Arch Otorhinolaryngol 2015;19:234-7.

7. Saruç M, Aksoy EA, Vardereli E, Karaaslan M, Çiçek $B$, Ince Ü et al. Risk factors for laryngopharyngeal reflux. Eur Arc Otorhinolaryngol 2012;269:118994.

8. Vavricka SR, Storck CA, Wildi SM, Tutuian R, Wiegand $N$, Rousson $V$ et al. Limited diagnostic value of laryngopharyngeal lesions in patients with gastroesophageal reflux during routine upper gastrointestinal endoscopy. American Journal of Gastroenterology. 2007;102:716-22.

9. Jiménez Fandiño LH, Mantilla Tarazona N, Ospina Díaz JA. Reflux laryngitis: an Otolaryngologist's perspective. Controversies in Gastroenterology 2011;26:193-200.

10. Groome M, Cotton JP, Borland M, McLeod S, Johnston DA, Dillon JF. Prevalence of laryngopharyngeal reflux in a population with gastroesophageal reflux. The Laryngoscope 2007;117:1424-8.

11. Giacchi RJ, Sullivan D, Rothstein SG. Compliance with anti-reflux therapy in patients with otolaryngologic manifestations of gastroesophageal reflux disease. The laryngoscope 2000;110:19-22.

12. Tauber S, Gross $M$, Issing WJ. Association of laryngopharyngeal symptoms with gastroesophageal reflux disease. Laryngoscope 2002;112:879-86.

13. Lowden M, McGlashan JA, Steel A, Strugala $V$, Dettmar PW. Prevalence of symptoms suggestive of extra-oesophageal reflux in a general practice population in the UK. Logopedics Phoniatrics Vocology 2009;34:32-5.

14. Çekin E, Ozyurt M, Erkul E, Ergunay K, Cincik $H$, Kapucu B, Gungor A. The association between Helicobacter pylori and laryngopharyngeal reflux in laryngeal pathologies. Ear, Nose \& Throat Journal 2012;91:E6-9.

15. Kamani T, Penney S, Mitra I, Pothula V. The prevalence of laryngopharyngeal reflux in the English population. Eur Arch Otorhinolaryngol 2012;269:2219-25.

16. Sabri Tezer M, Cem Kockar M, Koçkar O, Celik A. Laryngopharyngeal reflux finding scores correlate with gastroesophageal reflux disease and Helicobacter pylori expression. Acta Otolaryngologica 2006;126:958-61.

17. Hoon Park K, Myung Choi S, UK Kwon S, Won Yoon S, UK Kim S. Diagnosis of laryngopharyngeal reflux among globus patients. Otolaryngology Head and Neck Surgery 2006;134:81-5.

18. Park JH, Lee DH, Kim JY, Park SY, Yoon $H_{\text {, }}$ Park YS et al. Gastroesophageal reflux disease with laryngopharyngeal manifestation in Korea. Hepatogastroenterol 2012;59:2527-9.

19. Somefun OA, Wanda CB, Adesanya AA, Thomas $\mathrm{MO}$, Esan OO. Otolaryngologic manifestations of gastro-oesophageal reflux disease in Lagos. The Nigerian postgraduate medical journal 2006;13:225-9. 